\title{
Environmental Geological Problems in Southwest China: A Case Study from the Researches of Regional Landslide Hazards
}

\author{
Shuang $\mathrm{Li}^{*}$, Xiang $\mathrm{Wu}^{* *}$, Faming Sun ${ }^{* * * \dagger}$, Jie Yang*** and Jian $\mathrm{Li}^{* * *}$ \\ *College of Civil Engineering, Fuzhou University, Fuzhou 350108, China \\ **School of Public Administration, Zhongnan University of Economics and Law, Wuhan 430073, China \\ ***No. 205 Geological Team, Chongqing Bureau of Geology and Minerals Exploration, Chongqing 402160, China \\ $\dagger$ Corresponding author: Faming Sun; $33317801 @$ qq.com
}

\section{Nat. Env. \& Poll. Tech. \\ Website: www.neptjournal.com \\ Received: 19-04-2021 \\ Revised: $05-05-2021$ \\ Accepted: 08-06-2021 \\ Key Words: \\ Environmental geology \\ Southwest China \\ Landslide mechanism \\ Monitoring and prediction}

\begin{abstract}
Humans have paid a lot of attention to environmental geological challenges in recent years. Landslides, being one of the most prevalent geological disasters, are characterized by their suddenness and destructiveness. Southwest China is prone to landslides and debris flows due to its unique geological structure. This paper uses landslides in southwest China as an example, focusing on research on landslide initiation mechanisms and outlining modern landslide monitoring devices and prediction models. Landslides are caused by external variables such as persistent precipitation, groundwater movement, and significant seismic activity, as well as interior reasons such as fine particle rearrangement and the action of positive pore water. The reduction of the friction coefficient of the shear surface, which is induced by the increase of the shear rate, the supercritical carbon dioxide and superheated steam of the shear zone, and the mineral recrystallization process on the shear surface, all have an important impact on reducing the friction coefficient of the shear surface, is a key factor in the occurrence of highspeed remote landslides. Real-time landslide monitoring using space-air-ground and acoustic emission technology, as well as the creation of machine learning-based forecast models, have aided in the research of landslide development and early warning.
\end{abstract}

\section{INTRODUCTION}

Southwest China is located on the east side of the Qinghai-Tibet Plateau. Various geological factors have influenced the formation of a complex geological environment and valley dynamic conditions over time, including high ground stress, strong fault structure-activity, frequent strong earthquakes, the dynamic characteristics of a strong river in a deep-cut canyon, the complex rock-soil environment, and hydrogeological conditions, and the deep overburden of the river bed, among others. After the Wenchuan earthquake in 2008, the frequency of these geological disasters has increased significantly, which provided a lot of data for the study of debris flow (Li et al. 2021a, 2021b, 2021c, Peng et al. 2021, Hu et al. 2014, 2016, 2018a, 2018b, 2018c, 2018d, Liao et al. 2020, 2021, Liu et al. 2020, 2021, Chang et al. 2021).

The international definition of a landslide isn't agreed upon. Simply put, a landslide is a natural geological phenomenon in which the rock and soil mass on a slope slide downward along a weak surface or zone under the action of gravity (Nemok et al. 1972, Varnes 1978), and its action process is one of the manifestations of the geomorphology evolution process (Glade \& Crozier 2005, Irasema 2002).
The landslide's massive volume is usually large, which is owing not only to the rock and soil being transported by themselves but also to the entrainment effect of the landslide movement process, which causes the ultimate landslide body volume to be much larger than the initial volume (Gao et al. 2020). Because the dangers of landslides are self-evident, an in-depth study of existing landslides can guide future landslide prevention and management, and it is also a manifestation of humans learning from and modifying nature. Shao et al. (2020) studied the identification, classification, and characteristics of landslides in Baoshan City, Yunnan Province, China, and established a detailed landslide list, which provided the necessary basis for further study of landslide development and spatial distribution, landslide prediction, and geological disaster evaluation in Southwest China. According to satellite images, there was an ancient landslide in this area before 2008. Wasowski et al. (2021) studied the Yangjiagou landslide formed after Wenchuan Earthquake and combined it with the existing landslide research Finally, the seismic activity pattern in the surrounding area of the Longmenshan fault was inferred, and other works of literature also reported it (Ouimet 2010; Tang et al. 2011, 2012; Fan et al. 2018, 2020). Wang et al. (2021a, 2021b) 
conducted a field investigation and experimental research on the occurrence mechanism of the Donghekou landslide, and the results obtained were used to guide landslide research in Japan. iRALL also organized a thematic meeting on the issue of landslides after the 2008 Wenchuan earthquake (Huang et al. 2018).

In this paper, the current developments in the study of landslide occurrence mechanisms are strongly introduced, and finally, numerous approaches and models for landslide monitoring and prediction are summarized, with a focus on typical landslides in Southwest China. We know the landslide-prone locations, the landslide occurrence mechanism, expand the depth and breadth of the study mechanism and compare the accuracy of monitoring means and forecasting models from a macro perspective. It helps us to have an overall understanding of the existing prevention and control methods, to guide the prevention and control of landslide disasters.

\section{Landslide Mechanisms}

Influencing factor: The occurrence of landslide needs to meet specific mechanical conditions, that is, when the sliding resistance of the weak surface of landslide is less than the sliding force, a certain volume of rock and soil will move along the sliding surface. The mechanism of landslides is closely related to the inducing factors. Table 1 depicts the conditions that may cause a landslide from four perspectives.

Mechanisms of the Soil landslides: When the landslide material is made up of a loose accumulation of dirt, it would start up and move like water under the impact of an earthquake or a high-intensity continuous rain. To study its mechanism, Hu et al. (2017a, 2017b, 2018a, 2018b, 2019) experimented with artificial imitation particle slope in the laboratory and revealed the instability and failure mechanism of this system. Hu et al. $(2016,2019,2020)$ also believed that under gravity, a precise combination of normal stress and shear strain rate would cause dry particle flow to move, and that particle breaking would considerably lower following shear resistance due to particle thixotropy.

In addition to the influence of soil particle size, the excessive positive pore water pressure in a landslide is also considered as one of the important factors triggering landslide (Wang et al. 2020), so the monitoring of on-site pore water pressure can be used as a reliable indicator for landslide early warning (Hu et al. 2017a). Hu et al. (2017b) studied the influence of particle size and pore water on the start of landslides. As mentioned earlier, precipitation often plays a key role in the occurrence of landslides, and its time evolution has a positive correlation with the landslide process (Wang et al. 2019, Yang et al. 2019, Gao et al. 2020, Li et al. 2020). Besides precipitation, terrain factors also have a significate influence on the occurrence of landslides (Fan et al. 2020). For reservoir landslide, Wang et al. (2021a, 2021b) and Li et al. (2021a, 2021b, 2021c) have reached similar conclusions, namely, the dominant failure mechanism of landslide changes with the change of reservoir water level and slope saturation. The periodic fluctuation of reservoir water level, according to Liao et al. (2021), has a significant impact on the mechanical characteristics of the sliding zone soil in the water-fluctuating zone, and the area of the water-fluctuating zone regulates landslide stability. Xia et al. (2021) introduced a two-dimensional Discontinuous Deformation Analysis

Table 1: The factors affecting the occurrence of landslides (Cruden \& Varnes 1996).

\begin{tabular}{|c|c|c|c|}
\hline Geological factor & Geomorphological factors & Natural factors & Human factors \\
\hline soft rock-soil & Structure or volcanic uplift & Rainstorm & Excavation of slope and slope foot \\
\hline weathered rock & Ice cover spring back & Quick snowmelt & Loading weight on slope or slope top \\
\hline shear band cutting rock mass & $\begin{array}{l}\text { River erosion slope toe or its side } \\
\text { edge }\end{array}$ & continuous rainfall & reservoir construction \\
\hline Rock mass with developed joint fissures & Wind erosion slope toe & Flood or tidal impact & disafforestation \\
\hline $\begin{array}{l}\text { Reverse discontinuity surface ( fault, } \\
\text { unconformity surface, fracture, etc. ) }\end{array}$ & Ice erosion slope toe & Earthquake & irrigation \\
\hline $\begin{array}{l}\text { Significant difference in permeability } \\
\text { of rock-soil }\end{array}$ & $\begin{array}{l}\text { Underground erosion (dissolution } \\
\text { and sub-erosion) }\end{array}$ & volcanic eruption & Mining, quarrying \\
\hline \multirow{3}{*}{$\begin{array}{l}\text { Significant difference in the strength of } \\
\text { rock-soil }\end{array}$} & Vegetation destruction & melting ice & artificial vibration \\
\hline & $\begin{array}{l}\text { Slope or slope top stacking inter- } \\
\text { action }\end{array}$ & Freezing and dissolved & conduit leakage \\
\hline & & shrinkage and swelling & \\
\hline
\end{tabular}


(DDA) that may be used to mimic the fracture tensile behavior of rock in a rock avalanche generated by seismic force.

Mechanisms of the rock landslides: Rock landslides are also common in the Sichuan Basin and the Three Gorges area of China. The typical feature of this kind of landslides is the alternating layers of mudstone and sandstone in a bedding-control cataclastic slope. Hu et al. (2019, 2014, 2016) studied the starting mechanism of the Daguangbao landslide formed after the Wenchuan earthquake, it was found that the high temperature of $800^{\circ} \mathrm{C}$ was generated during the sliding process of the basement, which made dolomite thermally decompose to form lime $(\mathrm{CaO})$ and magnesia $(\mathrm{MgO})$ (Fig. 1 ), and some minerals in the shear zone were heated to form a dynamic recrystallization layer about $0.1 \mathrm{~mm}$ thick (Fig. 2).

In addition, hot supercritical carbon dioxide and superheated steam with a pressure of $>10 \mathrm{MPa}$ could produce high pore-fluid pressure, and the dynamic recrystallization of minerals and supercritical gas together constituted the drag reduction mechanism of landslide movement, which was consistent with Habib (1975) and Goguel (1978). As a result, quick long-run-out landslides are easy to form. Hu \& McSaveney (2018) and Hu et al. (2018b) then conducted extensive investigations into two rock failures in Jiweishan and came to the same result. This is because as soil saturation and shear rate increase, the residual friction coefficient of the soil decreases significantly, and the critical stress triggering large displacement is related to the residual shear strength related to soil rate (Hu et al. 2018a, Scaringi et al. 2018), while another paper (Xu et al. 2021) shows that under the action of larger normal stress $(>100 \mathrm{kPa})$, the soil in the slip zone is more likely to fail than the soil-bedrock interlayer.

\section{Landslide Monitoring and Prediction}

Landslide activity can be observed in all weathers using monitoring equipment based on the integration of space, air, and ground. Landslide prediction models have been swiftly constructed using a combination of statistics and computer science, and their accuracy and scope of application have been greatly upgraded and enlarged, as described in this study.

Monitoring technology: Interferometry Synthetic Aperture Radar (InSAR) is a real-time landslide monitoring system that has been successfully utilized for landslide monitoring in Southwest China (Zhang et al. 2021, Woods et al. 2021). $\mathrm{Hu}$ et al. (2018a) discovered a creep-like link between acoustic emission technology and density and cumulated acoustic energy of slope material by capturing and analyzing the high-frequency atomic spectrum generated by particle rearrangement in landslides. The literature also mentions sonic emission technology as an early warning approach for landslide monitoring (Xiaoyan et al. 2020). The dam height of the dammed lake generated by the second landslide is larger when more than two landslides occur in the same location on both bank slopes of the river, but its stability is lower (Liao et al. 2020). As a result, it is vital to estimate the landslide risk in the area, predict the likely dammed lake shape, and execute control measures ahead of time to minimize damage. As demonstrated in Tables 2, 3, and 4, it separates the monitoring technical principles, benefits, and drawbacks of space-air-ground monitoring.
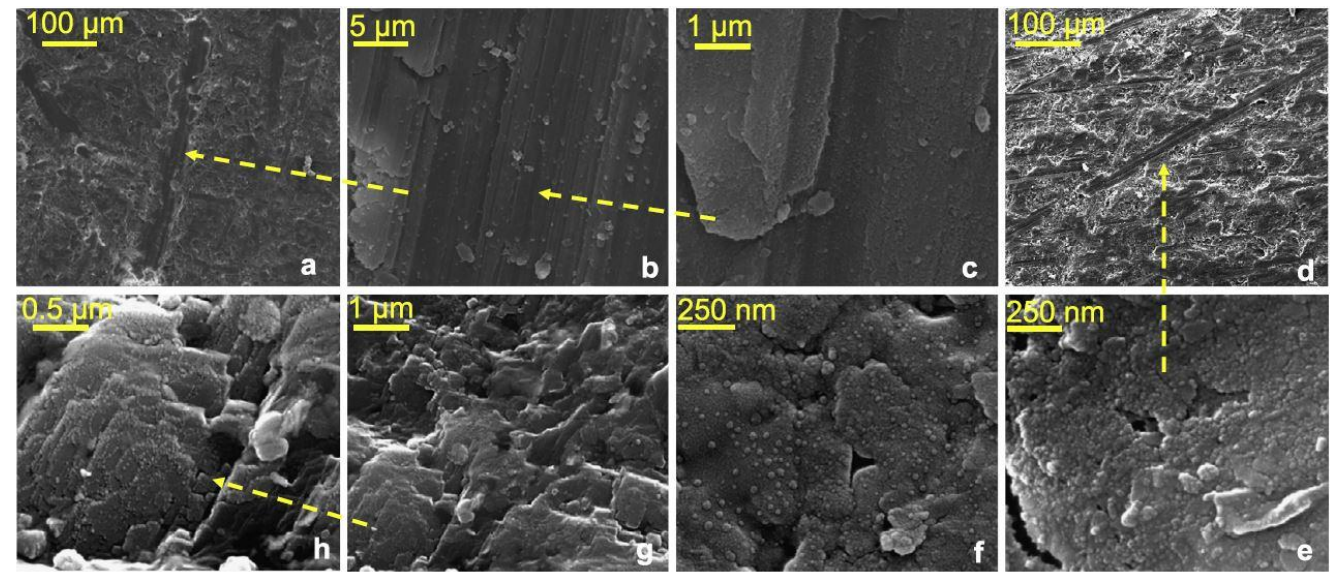

Fig. 1: Electronic image of sliding surface and internal structure in cataclastic dolomite near the sliding surface of Daguangbao landslide. a. Two sets of micro-scratches, vertical scratches indicate the direction of landslide movement; another group of scratches may be the direction of past tectonic movement. b. and c. Nano-sphere structure is a typical feature of dolomite decarbonization into lime $(\mathrm{CaO})$ and magnesia $(\mathrm{MgO})$. d. and e. The micro-scratch on the surface of another sample, which has a similar structure to b. and c. f. The nano-sphere structure found about $3 \mathrm{~mm}$ below the sliding surface indicates the source of recrystallized materials in b. c. and e. g. and h. The remains of formerly decomposed dolomite grains (now reconstituted) (Hu et al. 2019). 

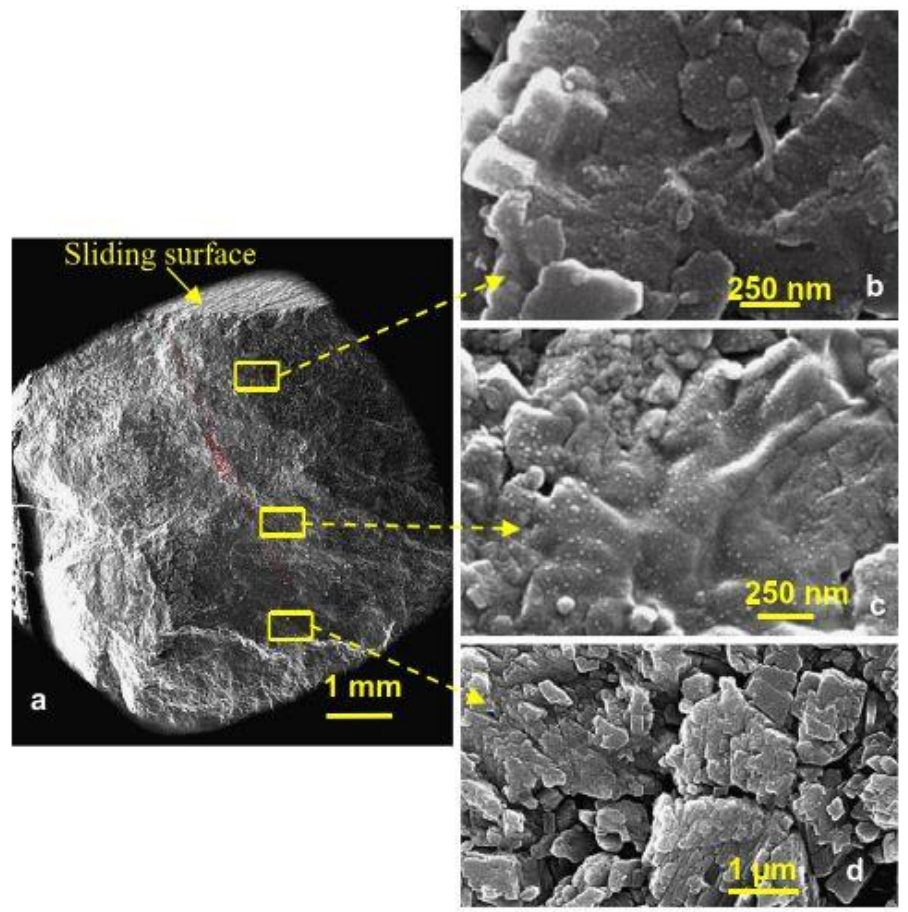

Fig. 2: Electronic images of internal structures at different depths under the sliding surface in cataclastic dolomite of Daguangbao Mountain. a. Dolomite fragments under the sliding surface. b. and c. Skeletal remains of extensively decomposed dolomite. d. Partially decomposed dolomite fragments covered with tiny spheres (nano- sphere) typical of thermal decarbonization of dolomite to lime $(\mathrm{CaO})$ and magnesia $(\mathrm{MgO})$ (but now carbonated in the nine years' exposure) (Hu et al. 2019).

Prediction models: It is far from sufficient to rely exclusively on monitoring technology to avoid and control landslides. Because precipitation has such a large impact on the commencement of a landslide, some researchers (Yang et al. 2019, Yu et al. 2020) suggested a precipitation threshold prediction model and verified its validity with existing data, resulting in an excellent prediction result. Liu \& Wang (2021) simulated the whole process of a landslide caused by rainfall, which provided a new perspective for the quantitative risk assessment (QRA) study of landslide-induced landslides. In recent years, machine learning has played an increasingly important role in fuzzy reasoning and data statistics. For instance, the neural network model (Abbaszadeh et al. 2020, Liu et al. 2021), neuro-fuzzy reasoning, and ant colony algorithm (Razavi-Termeh et al. 2021) have great advantages in evaluating landslide susceptibility. Zhou et al. (2018) combined the support vector machine (SVM) and artificial neural network (ANN) with multivariate statistical model logistic regression (LR) to propose the landslide susceptibility modeling (LSM). Goetz et al. (2015) and Chen et al. (2018) respectively selected six and four landslide sensitivity evaluation models based on machine learning. Sun et al.

Table 2: Monitoring methods on space.

\begin{tabular}{|llll|}
\hline Monitoring methods & Principle & Advantages & Disadvantages \\
\hline $\begin{array}{l}\text { Global Navigation Satellite } \\
\text { System, GNSS }\end{array}$ & $\begin{array}{l}\text { The position of the monitoring point is } \\
\text { acquired by satellite in real-time }\end{array}$ & $\begin{array}{l}\text { 24h-monitoring; } \\
\text { all-weather }\end{array}$ & $\begin{array}{l}\text { The number of monitoring stations } \\
\text { is limited and the data processing } \\
\text { process is complex }\end{array}$ \\
$\begin{array}{l}\text { Interferometry Synthetic aper- } \\
\text { ture radar, InSAR }\end{array}$ & $\begin{array}{l}\text { The image of the landslide is obtained by } \\
\text { SAR satellite, and then the three-dimen- } \\
\text { sional terrain information of the landslide is } \\
\text { obtained by processing the photo }\end{array}$ & $\begin{array}{l}\text { 24h-monitoring; } \\
\text { all-weather; high } \\
\text { precision }\end{array}$ & $\begin{array}{l}\text { It is difficult to select monitoring } \\
\text { points, which is affected by spatial } \\
\text { loss correlation and atmospheric } \\
\text { delay }\end{array}$ \\
$\begin{array}{l}\text { The UAV is equipped with a camera, flies } \\
\text { along the design route and takes pictures, and } \\
\text { then obtains a three-dimensional slope model } \\
\text { through the image data processing }\end{array}$ & $\begin{array}{l}\text { High precision, auto- } \\
\text { mation, intelligence, } \\
\text { not affected by clouds }\end{array}$ & $\begin{array}{l}\text { It cannot be monitored all-weather } \\
\text { due to the weather }\end{array}$ &
\end{tabular}


(2021) established two optimized landslide susceptibility mapping models (LSM): logistic regression (LR) and random forest (RF) based on Bayesian algorithm hyper parameter optimization. In terms of landslide distance prediction, Zhou et al. (2020) proposed an optimized neural network model whose advantages are significantly greater than the multiple regression model. Li et al. (2021a, 2021b) used PFC software to predict the runout behavior of landslides and provided a new method for landslide hazard risk assessment.

\section{CONCLUSION}

In this paper, the present situation of landslide research in Southwest China is summarized, with emphasis on the landslide starting mechanism, and a brief overview of landslide monitoring technology and prediction model.

1 . There are many factors contributing to the initiation of landslide, among which precipitation and earthquake are two major inducing factors. For soil landslide, precipitation leading to seepage in the landslide and fine particles recombined by water migration induces deformation of landslide to a certain extent. On the one hand, the stability of a landslide could be broken by an earthquake. On the other hand, the positive pore water pressure in a landslide may rise due to vibration, which will also trigger a landslide. Rock landslide has the characteristics of fast speed, long-distance, and large volume because high temperatures are generated in the shear zone of a landslide during movement, the minerals at a certain thickness of interface dynamically recrystallize, and high temperatures also produce supercritical carbon dioxide and superheated steam, lowering friction coefficient and friction resistance. The friction coefficient of the shear surface will also decrease with the increase of normal stress and shear rate during the movement of soil landslide.

2. It's a quick rundown of landslide monitoring and forecasting technology. Landslide monitoring technology evolves in tandem with scientific and technological advancements. Real-time landslide monitoring and accurate forecasting will advance to a new level if the integrated monitoring technology in the space-air-ground can be fully employed. The landslide prediction model is mainly based on statistical analysis and machine learning to make a landslide susceptibility model (LSM), combine the model with existing landslide data, and constantly adjust parameters to achieve

Table 3: Monitoring methods on air.

\begin{tabular}{|llll|}
\hline Monitoring methods & Principle & Advantages & Disadvantages \\
\hline Robot monitoring & $\begin{array}{l}\text { The total station automatically monitors the prism } \\
\text { on the landslide in 24 hours }\end{array}$ & $\begin{array}{l}\text { Automation, 24-hour moni- } \\
\text { toring, high precision }\end{array}$ & $\begin{array}{l}\text { The monitoring range of a single robot is } \\
\text { small, but the cost of arranging multiple } \\
\text { robots is high }\end{array}$ \\
3-D laser scanning & $\begin{array}{l}\text { By measuring the time difference between trans- } \\
\text { mitting and receiving laser and the horizontal } \\
\text { angle and zenith distance of each pulse laser, the } \\
\text { three-dimensional coordinates of the measured } \\
\text { object are obtained }\end{array}$ & $\begin{array}{l}\text { 24-hour dynamic monitor- } \\
\text { ing; high precision }\end{array}$ & $\begin{array}{l}\text { The data processing is complex and the } \\
\text { measurement accuracy is affected by } \\
\text { surface objects }\end{array}$ \\
& $\begin{array}{l}\text { The LIDAR sensor emits and receives microwave } \\
\text { signals, and the image is synthesized by SAR } \\
\text { technology. }\end{array}$ & $\begin{array}{l}\text { High precision; 24h mon- } \\
\text { itoring; all-weather; not } \\
\text { affected by the weather }\end{array}$ & $\begin{array}{l}\text { Lack of data processing; monitoring } \\
\text { environment has an impact on the results }\end{array}$ \\
GB-InSAR & & &
\end{tabular}

Table 4: Monitoring methods on ground.

\begin{tabular}{|c|c|c|c|}
\hline Monitoring methods & Principle & Advantages & Disadvantages \\
\hline $\begin{array}{l}\text { Time Domain Radiation, } \\
\text { TDA }\end{array}$ & $\begin{array}{l}\text { The deformation position and displacement } \\
\text { can be determined by processing the echo } \\
\text { signal. }\end{array}$ & $\begin{array}{l}\text { Short monitoring time, low } \\
\text { cost, and accurate position- } \\
\text { ing of sliding surface }\end{array}$ & $\begin{array}{l}\text { Unable to determine the position of } \\
\text { the sliding surface, low sensitivity } \\
\text { to uniform deformation, point style } \\
\text { monitoring }\end{array}$ \\
\hline Borehole inclinometer & $\begin{array}{l}\text { There is a certain angle between the incli- } \\
\text { nometer probe and the deformation of rock } \\
\text { and soil, and the horizontal displacement of } \\
\text { the inclinometer probe can be calculated by } \\
\text { using the angle. }\end{array}$ & $\begin{array}{l}\text { Accurately monitor the di- } \\
\text { rection of sliding surface }\end{array}$ & $\begin{array}{l}\text { Point monitoring, orientation is sus- } \\
\text { ceptible to interference }\end{array}$ \\
\hline Distributed fiber optic sensing & $\begin{array}{l}\text { Through the reception and analysis of scat- } \\
\text { tered light, the changes of strain and temper- } \\
\text { ature in optical fiber are obtained }\end{array}$ & $\begin{array}{l}\text { High precision, distributed } \\
\text { monitoring, high survival } \\
\text { rate, anti-corrosion and an- } \\
\text { ti-interference }\end{array}$ & $\begin{array}{l}\text { Unable to determine the direction of } \\
\text { sliding surface }\end{array}$ \\
\hline
\end{tabular}


the expected accuracy. However, due to the limitations of the existing technology, no model can accurately predict all types of landslide characteristics.

\section{AUTHOR CONTRIBUTION STATEMENT}

The authors confirm contribution to the paper as follows: Shuang Li: Conceptualization, Formal Analysis, Writing - Original Draft; Xiang Wu: Investigation, Data Curation, Writing - Original Draft; Faming Sun: Conceptualization, Supervision, Writing - Review \& Editing; Jie Yang: Investigation, Writing - Original Draft; Jian Li: Resources, Supervision.

\section{REFERENCES}

Abbaszadeh, S., Abbas, M. and Fardad, M.M. 2020. Landslide susceptibility mapping using hybridized block modular intelligence model. Bull. Eng. Geol. Environ., 80: 267-284.

Chang, M., Xiangyang, D., Tristram, C.H. and Bin, Y. 2021. Patterns of rainfall-threshold for debris-flow occurrence in the Wenchuan seismic region, Southwest China. Bull. Eng. Geol. Environ., 80: 2117-2130.

Chen, W., Peng, J., Hong, H., Shahabi, H., Pradhan, J., Liu, A., Zhu, X., Pei, C.X. and Duan, Z. 2018. Landslide susceptibility modeling using GIS-based machine learning techniques for Chongren County, Jiangxi Province, China. Sci. Total Environ., 626: 1121-1135.

Cruden, D.M. and Varnes, D.J. 1996. Landslide Types and Processes. Special Report - National Research Council, Transportation Research Board, 247: 36-75.

Fan, X., Junjie, T., Shujun, T. and Yuanjun, J. 2020. Rainfall-induced is rapid and long-runout catastrophic landslide on July 23, 2019, in Shuicheng, Guizhou, China. Landslides, 17: 2161-2171.

Fan, X., Hsein Juang, C., Wasowski, J., Huang, R., Xu, Q., Scaringi, G., Cees, J. and Hans-Balder, H. 2018. What we have learned from the 2008 Wenchuan Earthquake and its aftermath: A decade of research and challenges. Eng. Geol., 241 6: 25-32.

Gao, Y., Bin, L., Haoyuan, G., Lichuan, C. and Yongfu, W. 2020. Dynamic characteristics of high-elevation and long-runout landslides in the Emeishan basalt area: a case study of the Shuicheng "7.23" landslide in Guizhou, China. Landslides, 17: 1663-1677.

Glade, T. and Crozier, M.J. 2005. The nature of landslide hazard impact. Landslide Hazard Risk, 5: 43-74.

Goetz, J.N., Brenning, A, Petschko, H. and Leopold, P. 2015. Evaluating machine learning and statistical prediction techniques for landslide susceptibility modeling. Comp. Geosci., 81: 1-11.

Goguel, J. 1978. Scale-dependent rockslide mechanisms, with emphasis on the role of pore fluid vaporization. Develop. Geotech. Eng., 53: 985-1011.

Habib, P. 1975. Production of gaseous pore pressure during rock slides. Rock Mech., 7: 193-197.

Hu, W., Xu, Q., Wang, G.H., Van Asch, T.W.J. and Hicher, P.Y. 2016. Initiation processes for run-off generated debris flows in the Wenchuan earthquake area of China. Geomorphology, 253: 468-477.

Hu, W. and McSaveney, M.J. 2018. A polished and striated pavement formed by a rock avalanche in under $90 \mathrm{~s}$ mimics a glacially striated pavement. Geomorphology, 320: 154-161.

Hu, W., Xu, Q., Wang, G.H., Van Asch, T.W.J. and Hicher, P.Y. 2014. Sensitivity of the initiation of debris flow to initial soil moisture. Landslides, 12: $1139-1145$

Hu, W., Xu, Q., Wang, G.H., Van Asch, T.W.J. and Hicher, P.Y. 2020. Weakening rheology of dry granular flows with extensive brittle grain damage in high speed rotary shear experiments. Geophys. Res. Lett., 6: 47.
Hu, W., Runqiu, H., Mauri, M., Lu, Y., Qiang, X., Mingshi, F. and Xianghui, Z. 2019. Superheated steam, hot CO2, and dynamic recrystallization from frictional heat jointly lubricated a giant landslide: Field and experimental evidence. Earth Planet. Sci. Lett., 510: 85-93.

Hu, W., Runqiu, H., Mauri, M., Lu, Y., Qiang, X., Mingshi, F. and Xianghui, Z. 2018a. Mineral changes quantify frictional heating during a large low-friction landslide. Geology, 46: 223-226.

Hu, W., Runqiu, H., Mauri, M., Lu, Y., Qiang, X., Mingshi, F. and Xianghui, Z. 2018b. Acoustic emissions and microseismicity in granular slopes prior to failure and flow like motion: The potential for early warning. Geophy. Res. Lett., 45: 10406-10415.

Hu, W., Runqiu, H., Mauri, M., Lu, Y., Qiang, X., Mingshi, F. and Xianghui, Z. 2018c. Internal erosion controls failure and runout of loose granular deposits: Evidence from flume tests and implications for postseismic slope healing. Geophys. Res. Lett., 45: 5518-5527.

Hu, W., Runqiu, H., Mauri, M., Lu, Y., Qiang, X., Mingshi, F. and Xianghui, Z. 2018d. Suction and rate-dependent behavior of a shear-zone soil from a landslide in a gently-inclined mudstone-sandstone sequence in the Sichuan basin, China. Eng. Geol., 237: 1-11.

Hu, W., Xu, Q., Wang, G.H., Van Asch, T.W.J. and Hicher, P.Y. 2017a. Sensitivity of the initiation and runout of flow slides in loose granular deposits to the content of small particles: An insight from flume tests. Eng. Geol., 231: 34-44.

Hu, W., Qiang, X, Gonghui, W., Gianvito, S., Mauri, M. and Hicher, P.Y. 2017b. Shear resistance variations in experimentally sheared mudstone granules: A possible shear-thinning and thixotropic mechanism. Geophys. Res. Lett., 11: 44.

Huang, R., Xuanmei, F., Qiang, X., Gianvito, S., Wei, H., Niek, R. and Gonghui, W. 2018. The iRALL Doctoral School 2018: Advanced studies on large landslides on the 10th anniversary of the Wenchuan earthquake. Landslides, 15: 1901-1903.

Irasema, A. 2002. Geomorphology, natural hazards, vulnerability, and prevention of natural disasters in developing countries. Geomorphology, 47: 107-124.

Li, B., Wenping, G., Huiming, T., Zongxing, Z., Victor, M.B. and Hsein Juang, C. 2021a. Probabilistic analysis of a discrete element modeling of the runout behavior of the Jiweishan landslide. Int. J. Num. Anal. Methods Geomech., 32(7): 661-673.

Li, S., Guoping, L., Xiaofang, W., Chao, L., Haizhi, L. and Gang, Li. 2020. Precipitation characteristics of an abrupt heavy rainfall event over the complex terrain of southwest China were observed by the FY-4A satellite and doppler weather radar. Water, 12: 513.

Li, Y., Wei, H., Janusz, W., Yangshuai, Z. and Mauri, M. 2021b. Rapid episodic erosion of a cohesionless landslide dam: Insights from loss to scour of Yangjia Gully check dams and from flume experiments. Engineering Geol., 91: 180-187

Li, Y, Stefano, U., David, M., Lixia, C. and Kunlong, Y. 2021c. Chasing a complete understanding of the failure mechanisms and potential hazards of the slow-moving Liangshuijing landslide. Eng. Geol., 5: 281-296.

Liao, H., Xing-Guo, Y., Hai-bo, L., Bin-Rui, G. and Jia-wen, Z. 2020. Increase in hazard from successive landslide-dammed lakes along the Jinsha River, Southwest China. Geom. Nat. Hazards Risk, 11: 1115-1128.

Liao, K., Yiping Wu, Fasheng Miao, Linwei Li, and Yang, X. 2021. Effect of weakening of sliding zone soils in hydro-fluctuation belt on the long-term reliability of reservoir landslides. Bull. Eng. Geol Environ., 80: 3801-3815

Liu, M, Yong, Z., Shu-Feng, T., Ning-Sheng, C., Rahman, M. and Iqbal, J. 2020. Effects of loose deposits on debris flow processes in the Aizi Valley, southwest China. J. Mount. Sci., 17: 156-172.

Liu, Q., Guangyin, L. and Jie, D. 2021. Prediction of landslide displacement with step-like curve using variational mode decomposition and periodic neural network. Bull. Eng. Geol Environ., 80: 3783-3799.

Liu, X. and Wang, Y. 2021. Probabilistic simulation of the entire process of 
rainfall-induced landslides using random finite element and material point methods with hydro-mechanical coupling. Comp. Geotech., 9: 132.

Nemok, A., Paek, J. and Rybá, J. 1972. Classification of landslides and other mass movements. Rock Mech., 4: 71-78.

Ouimet, W.B. 2010. Landslides associated with the May 12, 2008, Wenchuan earthquake: Implications for the erosion and tectonic evolution of the Longmen Shan. Tectonophysics, 491(6): 244-252.

Peng, T., Chen, N.S., Hu, G., Tian, S. and Liu, E. 2021. New insights into the delayed initiation of a debris flow in southwest China. Nat. Hazards, 17: 227-236.

Razavi-Termeh, S.V., Kourosh, S. and Mehrdad, P. 2021. Mapping of landslide susceptibility using the combination of neuro-fuzzy inference system (ANFIS), ant colony (ANFIS-ACOR), and differential evolution (ANFIS-DE) models', Bull. Eng. Geol. Environ., 80: 2045-2067.

Scaringi, G., Wei Hu, Q.X. and Runqiu, H. 2018. Shear rate dependent behavior of clayey bimaterial interfaces at landslide stress levels. Geophys. Res. Lett., 45: 766-77.

Shao, X., Siyuan, M., Chong, X., Lingling, S. and Yongkun, L. 2020. Inventory, distribution, and geometric characteristics of landslides in Baoshan City, Yunnan Province, China. Sustainability, 12: 45-66.

Sun, D., Jiahui, X., Haijia, W. and Danzhou, W. 2021. Assessment of landslide susceptibility mapping based on Bayesian hyperparameter optimization: A comparison between logistic regression and random forest. Eng. Geol., 17: 281.

Tang, C., Van Asch, T.W.J., Chang, M., Chen, G.Q., Zhao, X.H. and Huang, X.C. 2012. Catastrophic debris flows on 13 August 2010 in the Qingping area, southwestern China: The combined effects of a strong earthquake and subsequent rainstorms. Geomorphology, 6: 559-576

Tang, C., Jing Zhu, X.Q. and Jun, D. 2011. Landslides induced by the Wenchuan earthquake and the subsequent strong rainfall event: A case study in the Beichuan area of China. Eng. Geol., 122(6): 22-33.

Varnes, D.J. 1978. Slope movement and types and processes. Landslides Anal. Cont., 16: 711-728.

Wang, D., Mengliang, L., Xing, Z, Hongsheng, M., Qiang, Cheng, M., Zhu, Z.C. and Chaojun, O. 2019. Failure mechanisms and deformation processes of a high-locality landslide at Tonghua Town, Li County, China, 2017. Landslides, 17: 165-177.

Wang, D., Mengliang, L., Xing, Z, Hongsheng, M., Qiang, Cheng, M., Zhu, Z.C. and Chaojun, O. 2021a. The debris avalanche in Donghekou area triggered by the 2008 Wenchuan (M8.0) earthquake: Features and possible transportation mechanisms. Eng. Geol., 14: 280.

Wang, L., Wenhua, L., Wei Hu, W. and De'an, S. 2020. Effects of seis- mic force and pore water pressure on the stability of 3D unsaturated hillslopes. Nat. Hazards, 105: 2093-2116.

Wang, S., Yuchen Pan, L., Wang, F.G., Yushan, C. and Wenduo, S. 2021 b. Deformation characteristics, mechanisms, and influencing factors of hydrodynamic pressure landslides in the Three Gorges Reservoir: a case study and model test study', Bulletin of Engineering Geology and the Environment, 80: 3513-33.

Wasowski, J., McSaveney, M.J., Pisano, L., Del Gaudio, V., Li, Y. and Hu, W. 2021. Recurrent rock avalanches progressively dismantle a mountain ridge in Beichuan County, Sichuan, most recently in the 2008 Wenchuan earthquake. Geomorphology, 41: 374.

Woods, A., Macciotta, M.T., Hendry, T., Stewart, M. and Marsh, J. 2021. Updated understanding of the deformation characteristics of the Checkerboard Creek rock slope through GB-InSAR monitoring. Eng. Geol., 281(6): 105974.

Xia, M., Guangqi, C., Pengcheng, Y., Xinyan, P. and Jinfeng, Z. 2021. Improvement of DDA with a new unified tensile fracture model for rock fragmentation and its application on dynamic seismic landslides. Rock Mech. Rock Eng., 54: 1055-1075.

Xiaoyan, Z., Hu, W., Zheng, Y., Gou, H. and Gao, X. 2020. Effects of relative density in progressive sliding of tailings deposits: insights from flume tests. Eng. Geol., 6: 279.

Xu, Q., Weizao, W., Litao, L. and Yingdong, C. 2021. The failure mechanism of gently inclined shallow landslides along with the soil-bedrock interface on ring shear tests. Bull. Eng. Geol. Environ., 80: 3733-3746.

Yang, H., Fangqiang, W. and Shaojie, Z. 2019. Rainfall threshold for landslide activity in Dazhou, southwest China. Landslides, 17: 61-77.

Yu, B., Erlong, M., Jiajun, C. and Guang, Z. 2020. A prediction model for rock planar slides with large displacement triggered by heavy rainfall in the Red bed area, Southwest, China. Landslides, 18: 773-783.

Zhang, T., Shuai, X., Jinghui, F., Bo, H., Qun, W., Weilin, Y., Hongli, Z., Jianping, C., Hongzhou, L. and Liqiang, T. 2021. Detection of active landslides in Southwest China using Sentinel-1 and ALOS-2 Data. Proc. Comp. Sci., 181: 1138-1145.

Zhou, C., Kunlong, Y., Ying, C., Bayes, A., Yuanyao, L., Filippo, C. and Hamid, R.P. 2018. Landslide susceptibility modeling applying machine learning methods: A case study from Longju in the Three Gorges Reservoir area, China. Comp. Geosci., 112: 23-37.

Zhou, H., Yong, C. and Ruoying, T. 2020. Distance prediction of slope-foot landslide in the southwest of China based on GA-BP neural network. IOP Conf. Ser. Mater. Sci. Eng., 11: 730. 